\title{
Wireless Home Energy Meter Manager Using Android: A Preliminary Study
}

\section{Sh. Nurul Hidayah Wan Julihi ${ }^{1}$, Ili Najaa Aimi Mohd Nordin ${ }^{1 *}$, Muhammad Rusydi Muhammad Razif ${ }^{1}$ and Amar Faiz Zainal Abidin ${ }^{2}$}

\author{
${ }^{1}$ Department of Electrical Engineering Technology, Faculty of Engineering Technology, Universiti Tun Hussein Onn \\ Malaysia, 84600 Pagoh, Johor, Malaysia. \\ ${ }^{2}$ Department of Automatic Control and Systems Engineering, Faculty of Electrical and Electronics Engineering Technology, \\ Universiti Teknikal Malaysia Melaka, 76100 Durian Tunggal, Melaka, Malaysia.
}

*Corresponding author: ilinajaa@uthm.edu.my

\begin{abstract}
Manual home energy meter reading and billing had caused inconvenience to the utility companies due to lack of manpower to read the energy meter at each household especially in the remote area, explains the increasing number of smart meter reader in the current market. Most of the smart meters in the market do not offer safety of privacy of consumers' personal information since the data of electricity usage is being transferred digitally to the utility companies for more accurate bills calculation. Plus, the smart meter system is also a bit pricey to be installed in the rural area. Therefore, a private system that able to read energy consumption from a DC load and calculate its bill according to the tariff is proposed. Value of current is being obtained by using ACS712 current sensor. Hall circuit in the current sensor will converts magnetic field into a proportional voltage. The proposed system allows energy meter monitoring from an Android-based smartphone by displaying the real-time energy consumption and bill on Blynk application. An interface of Blynk is developed and connected to WiFi module, ESP8266 for visualizing the energy consumption of the DC load. In conclusion, the Energy Meter transmitter part able to read, calculate and transmit value of energy consumption and current bills to the Blynk application and Blynk application able to receive and show all the data transmitted at the present time. This system will be further improved for longdistance monitoring of electrical appliances used at home.
\end{abstract}

Keywords: ACS712, Arduino UNO, Blynk, ESP8266, wireless home energy meter.

(C) 2019 Penerbit UTM Press. All rights reserved

Article History: received 4 September 2019; accepted 1 December 2019; published 24 December 2019.

\section{INTRODUCTION}

In the early days, meter reading for electricity consumption and billing are done manually by human operator. This would cause inconvenience to the utility companies such as lack of manpower as a meter reader must be on-site to take its reading [1]. This method may cause delay in meter reading and very time consuming [2]. This is because of the process of preparing the bill by the utilities company are affected if the house owner is absence such that it preventing the meter readers from the utilities company to enter the house for meter reading [1]. This will also cause inconvenience to their consumers as they will only receive their utilities bill once every month. The consumers are unable to monitor the real-time energy and power consumption of their household which could lead to waste of electricity and have to pay more for their utilities bill.

As in Figure 1, it is shown that electricity in Malaysia is generated from burning resources such as natural gas, coal and coke and also petroleum products which have a huge impact on the environment [3]. Burning natural gas produce fewer emissions of nearly all types of air pollutants and carbon dioxide $\left(\mathrm{CO}_{2}\right)$ than burning coal or petroleum products to produce an equal amount of energy [4]. This explain why natural gas is used more than other resources. As shown in Figure 2, the electric power sector accounted for about $36 \%$ of United States (U.S.) natural gas consumption in 2016 [4]. According to Malaysian Energy Commission in Figure 3, the electricity consumption by residential has steadily increased from year 2010 until 2015 remark that electricity demand is increasing yearly [3].

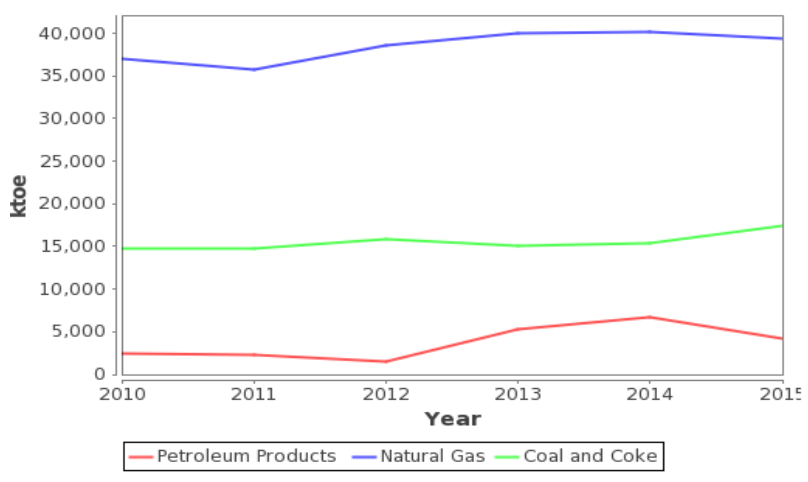

Figure 1. Primary energy supply [3]

In order to meet growing demand, technology must be implemented in the energy distribution to boost our life 
standards. Nowadays we have been introduced to Automatic Meter Reading (AMR) system and there is increasing demand for it as it can automatically collect meter reading electronically [1]. AMR consist of three main elements which are consumption measurement, transmission of measured data and data processing and billing. When using AMR, it will effectively reduce reading error or inaccuracy, fast meter reading and on realtime.

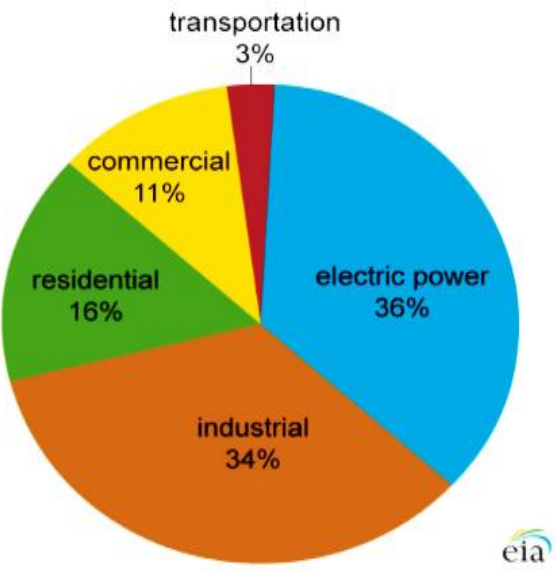

Figure 2. U.S. natural gas consumption in 2016 [4]

\begin{tabular}{|c|r|}
\hline \multirow{2}{*}{ Year } & $\begin{array}{c}\text { Final Electricity } \\
\text { Consumption } \\
\text { (ktoe) }\end{array}$ \\
\cline { 2 - 2 } & Residential \\
\hline 2010 & 1,937 \\
\hline 2011 & 1,974 \\
\hline 2012 & 2,126 \\
\hline 2013 & 2,262 \\
\hline 2014 & 2,346 \\
\hline 2015 & 2,435 \\
\hline
\end{tabular}

Figure 3. Residential electricity consumption [3]

In late 2006, smart meters were introduced to customers. According to several sources, smart meter can communicate in both directions, i.e. the meter can transmit information to the utility and the utility can also send information to the meter [5]. In order to have access to control and monitor appliances remotely, this project propose using WiFi as its network connection and is being implemented by using ESP8266, a WiFi module instead of using Ethernet in a wired home power meter.

Electric energy played an important role in our daily life since most of our home appliances is power up by using electrical energy. This scenario will be a disadvantage to the household consumer in this current economy where the price of daily basic needs has spiked up. The current technology that is available in Malaysia does not provide access to house owner to monitor and manage electricity usage from a distance by only by using application on their smartphones. This is because the energy and power consumption reading will go directly to the electricity company, Tenaga Nasional Berhad (TNB), to be stored in their database and the consumer will only receive their electricity bill by the end of the month without the ability to monitor and control their daily energy consumption. Therefore, user cannot estimate amount of total bill by the end of the month.

In the year of 2013, researchers from National Institute of Technology, Calicut, India came up with a project on Global System for Mobile Communications (GSM) Based Automatic Energy Meter Reading System with Instant Billing [1]. They used digital power meter to read energy used in each appliances and record it continuously then send through GSM network to billing server of the energy provider side to generates bill and lastly it will be send to user with GSM receiver [1]. The proposes system allows user to monitor their monthly power consumption and its round up bill either on a Liquid Crystal Display (LCD) display, via web portal or by receiving Short Message Services (SMS). This system still lacking in many aspects such that every SMS received by the user is charged at standard SMS rate [1]. It also does not provide an interactive GUI for user to control their appliances remotely. To reduce the risk of the missing the hard copies of the generated bill through postal mail, a soft copy of bill can be send to consumers if they are registered with their e-mail addresses [1].

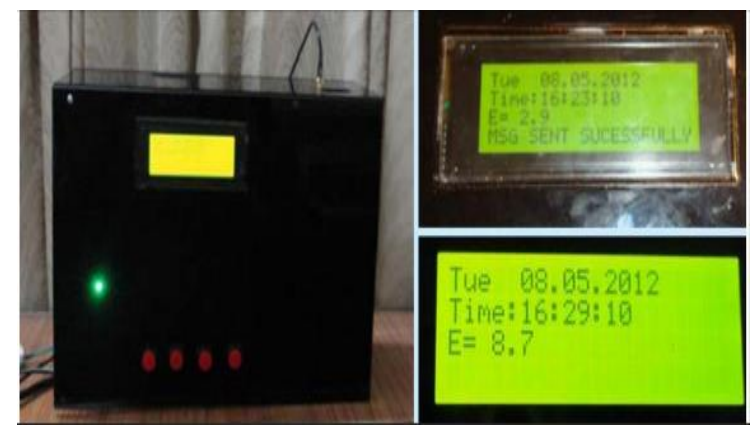

Figure 4. GSM meter and sample results on display [1]

Since cellular network coverage is now reachable even in a remote area, it has been proposed by researchers so that the monitoring can be done through Android application which is connected to the Internet. This method is used by researchers in the previous project in which they connect a few number devices to their relay board and control circuit so that they can monitor the status of the devices on the Android application [7]. ESP8266 NodeMCU WiFi shield was used to send the data received at the Arduino UNO (from its control circuit) via Internet to the Android application. Its Android application is designed so that it will shows the same switch as in the web server as shown in Figure 5 [7].

Another method used by researchers in order for wireless monitoring of the appliances is by using Bluetooth technology. Most of the researchers uses controller circuit or Home Energy Management (HEM) connected to home network to continuously monitor the value of energy consumption [6]. Some of the researchers measures the reading manually by using control circuit and some of them uses smart meter to obtain the value of energy consumption. 


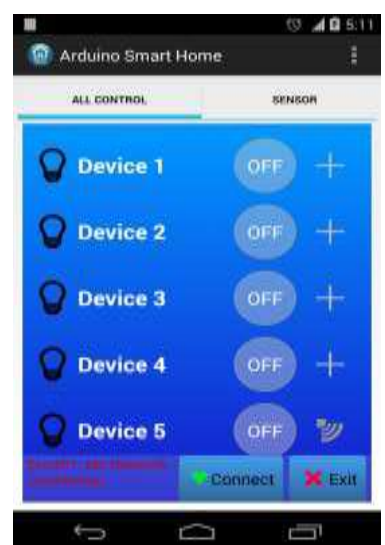

Figure 5. Screen shot of Android GUI of the proposed system [7]

The energy consumption values from the smart meter is send to utility company's billing server to calculate the bill for the energy consumption used according to the current tariff [1]. The latter is risky such that it can be manipulated by an irresponsible individual in order to gain benefits. Therefore, to be cautious, the first option is safer because all the steps, starts from energy meter reading and bill calculating to sending it to the user is manual. Considering it uses control circuit to read energy consumption, a microcontroller to calculate on the bills and using a personal network to send the information to the user.

Based on the previous research, most of them can monitor energy consumption either via SMS or LCD display [1] or Android application [2], [3] but does not calculate the round up bill for energy consumption used.

In order to improve the previous system in the previous research, this project proposed wireless home energy meter manager so that user have the ability to monitor household energy and power usage and estimating the total amount of bill by the end of the day through Blynk. This allow them to manage their household energy and power consumption more efficiently and manage their monthly budget.

\section{METHODOLOGY}

The proposed system is as shown in Figure 6. The schematic diagram circuit is designed and supposed to works accordingly. In this proposed system, different power supply is used to power up Arduino UNO and the load, which is a bulb. Arduino UNO will be power up plugging into laptop USB and the bulb is using a 9V DC battery. In order to calculate energy consumption, three parameters of Voltage $(\mathrm{V})$, Power $(\mathrm{P})$ and Time $(\mathrm{t})$ are needed since $\mathrm{P}=\mathrm{I}(\mathrm{V})$ and $\mathrm{E}=\mathrm{P}(\mathrm{t})$.

Current (I) will be measured by using Hall Effect current sensor ACS712 (5 Ampere) with 185 mV/A sensitivity. Hall Effect circuit is when a magnetic field is generated by the current flowing through the copper conduction path which will be converted to a proportional voltage value by the Hall IC. But the voltage value produce by the Hall IC is in analog signal. This output analog signal will be send to the analog pin of Arduino UNO. Now we can obtain a digital voltage value by using Arduino UNO.

Seeing as Arduino UNO now has both the value of I and $\mathrm{V}$, the $\mathrm{V}$ here is the household voltage supply and is a fixed value. Therefore, the value of $\mathrm{P}$ can be calculated. Whereby for the time parameter, Arduino UNO has a builtin timer. So technically Arduino UNO will be able to calculate the value of energy consumed, E since all three parameters are available. The value of $E$ is then will be calculated according to the current tariff to calculate the bill (B), where, $\mathrm{B}=\mathrm{E}^{*}$ (tariff). All of the processed data is then send from Arduino UNO to Android application through ESP8266 WiFi module.

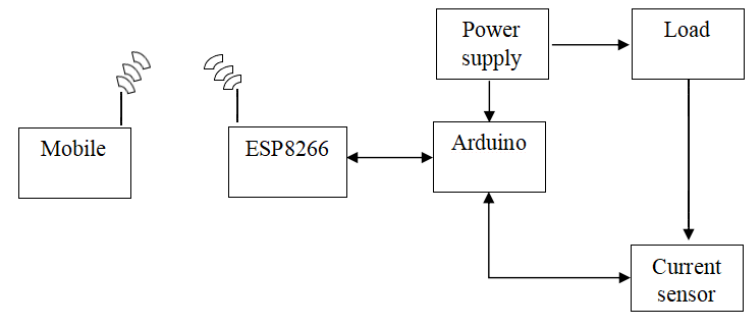

Figure 6. Block diagram of the proposed system

The first phase of this project is to develop wireless communication between ESP8266 and Blynk. For wireless LED light controlling, soft Access Point (SoftAP) mode is use. SoftAP is actually an abbreviated term for "software enabled access point", this is when computer or smart phone is used as WiFi access point without having to connect to a separate wireless router. ESP8266 ESP-01 does not come with a FTDI (Future Technology Devices International) chip, but when connect with Arduino UNO it will boost its WiFi ability as any WiFi shield would offers. That is why Arduino UNO is use in this proposed system and also in the first phase of this project where we use it to set up a fix connection between the ESP8266 module and WiFi hotspot.

\section{RESULTS AND DISCUSSION}

After the source codes were uploaded to the Arduino UNO, the wireless connection between ESP8266 and the WiFi hotspot can be checked through serial monitor window as shown in Figure 7. The serial monitor can be opened by simply click on the tool's tab located at the top right of the Arduino UNO IDE window and change the serial baud rate to be 115200 , the same setting like in ESP8266 transceiver. The next thing that can be changed is the enter key emulation, for this case "Both NL \& CR" was used.

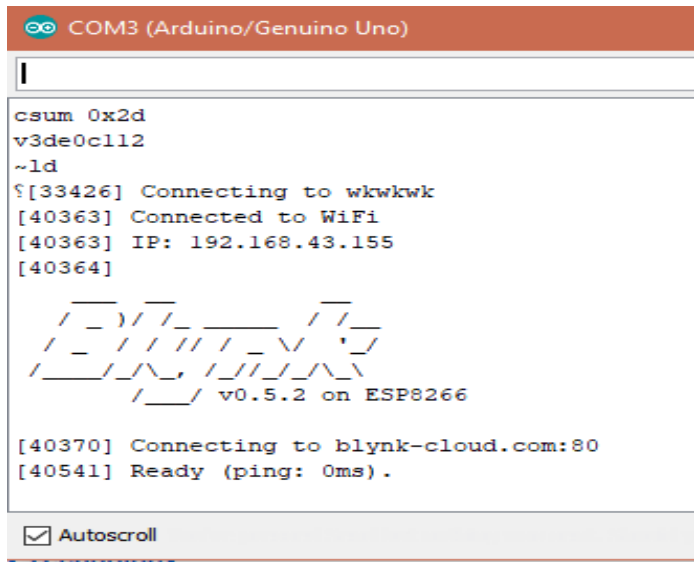

Figure 7. Serial monitor 
After the source codes have been uploaded to ESP8266 through Arduino UNO, GPI0 pin of ESP8266 was plugged out from the ground port as in Figure 8 (a) in order for the system to function as in Figure 9.

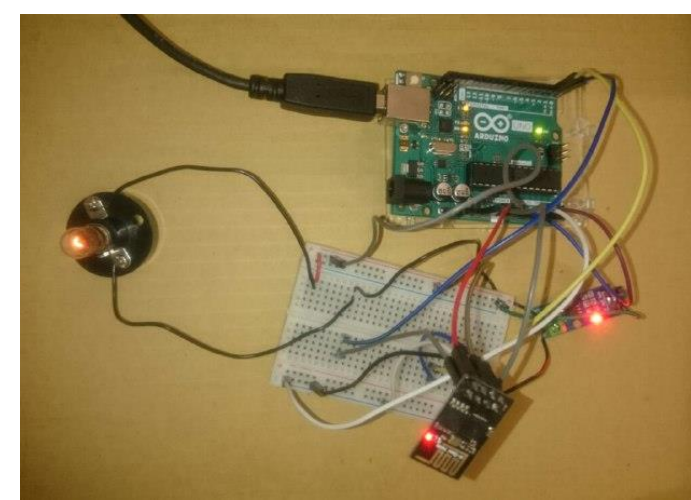

(a)

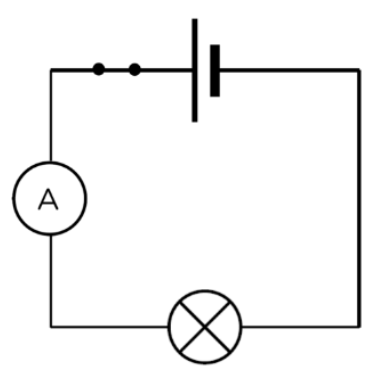

(b)

Figure 8. (a) Hardware of the proposed system (b) Ammeter connection

The maximum voltage can be supplied to the bulb is 9 $\mathrm{V}$ and its rated power is $3 \mathrm{~W}$. Therefore, the maximum current supply to the bulb is limited to only $0.33 \mathrm{~A}$. To limit current to the bulb, voltage of $5 \mathrm{~V}$ from the Arduino UNO is supplied to the load. Figure 9 and 10 displays zero value of current with an open circuit load connection, which prove that the current sensor ACS712 has been compensated from its analog-to-digital offset error \pm 0.02 A before it starts measuring current. In a close circuit connection, 0.13 A was measured when the load is supplied with a voltage of $5 \mathrm{~V}$ from voltage supply port. The accuracy of the ACS712 measurement can be calculated by comparing the current value measured by ammeter with the current value measured by current sensor ACS712 displayed at the serial monitor.

Ammeter was placed in between the positive port of voltage supply and the bulb, as shown in Figure 8 (b). The accuracy of the ACS712 current sensor can be calculated theoretically using Equation (1) and (2). The results are tabulated in Table 1. It is proven that the current measured from the current sensor ( $\mathrm{I}_{\text {MEASURED }}$ ) is very near to the expected value ( $\mathrm{I}_{\text {EXPECTED}}$ ), measured from the ammeter, with $97.62 \%$ of accuracy in average.

$$
\operatorname{Error}(\%)=\left|\frac{\left(I_{\text {EXPECTED }}-I_{\text {MEASURED }}\right)}{I_{\text {EXPECTED }}}\right| \times 100
$$

$$
\operatorname{Accuracy}(\%)=100 \%-\operatorname{Error}(\%)
$$

The time input in this system will start adding up when the load is switched on and will stop when the load is switched off. Information in Figure 9 and 10 proved that the wireless transmission from ESP8266 to Blynk is successful and does not lag. Five measurements were taken and are shown in Table 2.

Table 1. Current measured by ammeter and current sensor

\begin{tabular}{|c|c|c|c|}
\hline $\begin{array}{c}\text { Time } \\
\text { (minutes) }\end{array}$ & $\begin{array}{c}\text { IEXPECTED } \\
(\mathrm{A})\end{array}$ & $\begin{array}{c}\text { IMEASURED } \\
(\mathrm{A})\end{array}$ & $\begin{array}{c}\text { Accuracy } \\
(\%)\end{array}$ \\
\hline 5 & 0.13 & 0.13 & 100 \\
\hline 10 & 0.13 & 0.12 & 91.67 \\
\hline 15 & 0.13 & 0.13 & 100 \\
\hline 20 & 0.13 & 0.13 & 100 \\
\hline 25 & 0.13 & 0.13 & 100 \\
\hline 30 & 0.13 & 0.14 & 92.86 \\
\hline 35 & 0.13 & 0.13 & 100 \\
\hline 40 & 0.13 & 0.13 & 100 \\
\hline 45 & 0.13 & 0.12 & 91.67 \\
\hline 50 & 0.13 & 0.13 & 100 \\
\hline
\end{tabular}

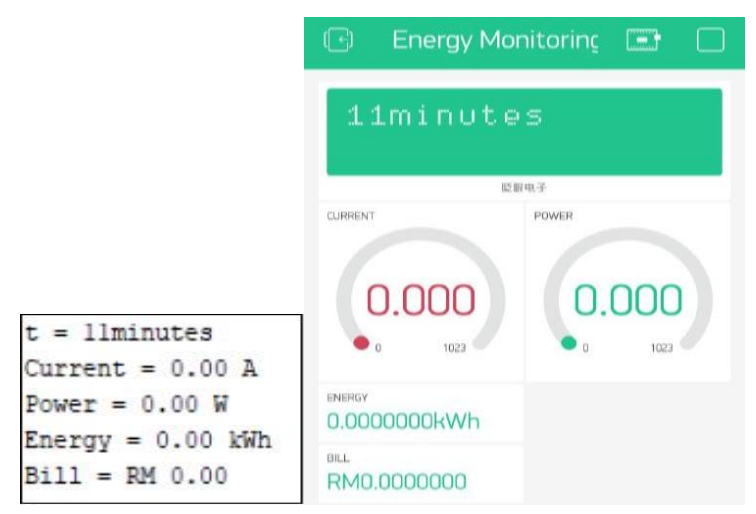

(a)

(b)

Figure 9. (a) Current, power, energy and bill measured by the ACS712 displayed at serial monitor when open circuit. (b) Current, power, energy and bill measured by the ACS712 displayed at Blynk application when open circuit.

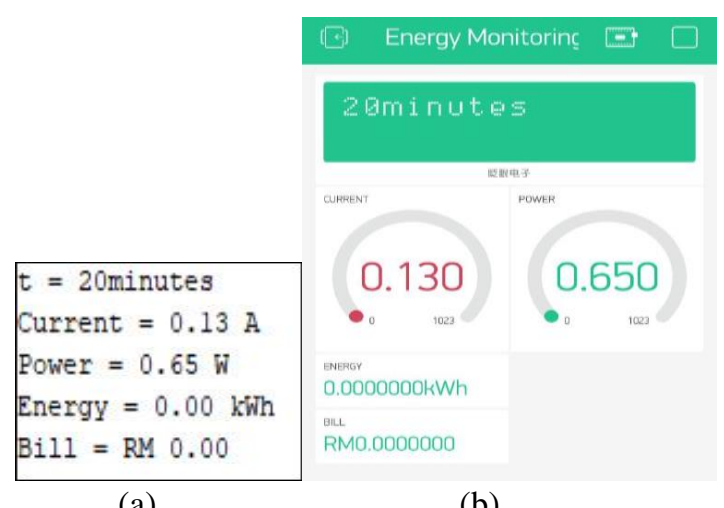

(a)

(b)

Figure 10. (a) Current, power, energy and bill measured by the ACS712 displayed at serial monitor in closed loop

configuration (b) Current, power, energy and bill measured by the ACS712 displayed at Blynk application in closed loop configuration. 
Table 2. Current transmitted from ESP8266, (IMEASURED) displayed on serial monitor and current received at smartphone ( $\mathrm{I}_{\mathrm{BLYNK}}$ ) displayed at Blynk application when circuit is closed.

\begin{tabular}{|c|c|c|}
\hline $\begin{array}{c}\text { Time } \\
\text { (minutes) }\end{array}$ & $\begin{array}{c}\text { IMEAsURED } \\
(\mathrm{A})\end{array}$ & $\begin{array}{c}\text { IBLYNK } \\
(\mathrm{A})\end{array}$ \\
\hline 10 & 0.12 & 0.12 \\
\hline 20 & 0.13 & 0.13 \\
\hline 30 & 0.14 & 0.14 \\
\hline 40 & 0.13 & 0.13 \\
\hline 50 & 0.13 & 0.13 \\
\hline
\end{tabular}

\section{CONCLUSION}

In a nutshell, the proposed wireless low current DC load energy meter measurement with bill estimation system is successfully built and shows high accuracy in current measurement using ACS712-5A current sensor and wireless data transmission using ESP8266 Wifi module. This system is relevant to be built to increase consumer awareness on the energy consumption. For future improvement, continuous time measurement even when the load is turned off can be implemented to this system. It can also be improved in such a way so that user can measure current consumption and control specific AC appliance from afar.

\section{ACKNOWLEDGMENT}

This work was supported by funding from the Ministry of Education Malaysia and Universiti Tun Hussein Onn Malaysia under the Tier 1 grant (Vot. No. H121). The approved fund has made this important research viable and effective.

\section{REFERENCES}

[1] K. Ashna and Sudhish N. George, "GSM based automatic energy meter reading system with instant billing," Proc. International Mutli-Conference on Automation, Computing, Communication, Control and Compressed Sensing (iMac4s), India, 2013, pp. 65-72.

[2] Y.-S. Son, T. Pulkkinen, K.-D. Moon, and C. Kim, "Home energy management system based on power line communication," IEEE Transactions on Consumer Electronics, vol. 56, no. 3, pp. 1380-1386, August 2010.

[3] (2011). Suruhanjaya Tenaga. Accessed on May 2018. [Online]. Available: http://meih.st.gov.my/statistics

[4] (2017). U.S. Energy Information Administration. Accessed on May 2018. [Online]. Available: https://www.eia.gov/energyexplained

[5] R. Gerwen, S. Jaarsma, and R. Wilhite, "Smart Metering," Leonardo Energy, vol. 1, no. July, pp. 19, July 2006.

[6] B. Yener, A. Taşcıkaraoğlu, O. Erdinç, M. Baysal, and J. Catalão, "Design and Implementation of an Interactive Interface for Demand Response and Home Energy Management Applications," Appl. Sci., vol. 7, no. 641, pp. 1-16, June 2017.

[7] J. C. A, R. Nagarajan, K. Satheeshkumar, N. Ajithkumar, P. A. Gopinath, and S. Ranjithkumar, "Intelligent Smart Home Automation and Security System Using Arduino and Wi-fi," Int. J. Eng. Comput. Sci., vol. 6, no. 3, pp. 20694-20698, March 2017. 